\title{
Plus ça change, plus c'est la même chose
}

\author{
Kate L. Lapane, PhD MS \\ Department of Quantitative Health Sciences University of Massachusetts Medical School, \\ Worcester, MA
}

Reading the study by Haider and colleagues ${ }^{1}$ in this issue of Medicare Care provoked profound frustration and despair. Frustration because of limited progress towards the Healthy People 2020 goal "to achieve health equity, eliminate disparities, and improve the health of all groups". ${ }^{2}$ Despair because of the realization that descriptive scientific work has little ability to change pervasive racial/ethnic healthcare disparities. Fifty years ago, Dr. Martin Luther King was purported to have said "Of all the forms of inequality, injustice in health care is the most shocking and inhuman."3 Agreed. Critiquing the disturbing work by Todd et al ${ }^{4}$ as a graduate student opened the Pandora's box of social injustice in healthcare to which I had been ignorant. The unacceptable truth is that sweeping, widespread change to promote equity in health care in the United States has not occurred. Not with the election of President Obama. Not with the enactment of the Affordable Care Act.

Haider and colleagues ${ }^{1}$ conducted a careful analysis of race/ethnicity-based disparities in pain management for adults presenting to emergency departments with acute abdominal pain. Using the National Hospital Ambulatory Care Survey (NHACS), the authors provide nationally representative estimates showing that analgesics were less frequently provided to Non-Hispanic Blacks relative to Non-Hispanic White patients, and that the differences were observed in patients with moderate/severe pain.

That the disparities in receipt of analgesics were not diminished with increasing pain severity is sickening. The 2011 Institute of Medicine report "Relieving Pain in America" recognizes the challenges of managing pain and called for a cultural transformation in understanding and managing pain. ${ }^{5}$ The NHACS data do not permit further exploration of reasons that give rise to the observed disparities. So, we don't know if evidence-based strategies to reduce disparities ${ }^{6}$ could be applied to the setting of pain management in the emergency room. It is clear that the emergency department provides the high pressure environment for implicit bias - insentient negative bias towards people of color - to rear its ugly head. A recent systematic review revealed low to moderate levels of implicit bias were prevalent among healthcare providers ${ }^{7}$ and noted that the "automatic activation" of implicit bias is most likely exhibited when people are tired, busy, and pressured. The context ripe for implicit bias is typified by emergency department setting, yet the evidence-base on how to reduce healthcare provider bias is "virtually absent".

Address correspondence and reprint requests to: Kate L. Lapane, PhD MS, Department of Quantitative Health Sciences, University of Massachusetts Medical School, Worcester, MA 01655, kate.lapane @umassmed.edu. 
Some have posited that public reporting of quality indicators may lead to standardized healthcare provision which could ultimately reduce healthcare disparities by race/ethnicity. One of the Centers for Medicare \& Medicaid Services Hospital Compare publicly reported quality indicators relates to care provided in the emergency department. ${ }^{8}$ Unfortunately, the evidence base supporting public reporting as a viable avenue for ending health disparities is lacking. ${ }^{9}$

Haider et al ${ }^{1}$ provide data on emergency department characteristics giving rise to differential treatment on the basis of skin color. Emergency departments in metropolitan areas, servicing a high proportion of racial/ethnic minority patients which are non-profit appear to be particularly prone to racial disparities in analgesic receipt. Racial disparities persisted in emergency departments with the highest tertile of patients reporting severe pain. Such data provide interventionists with information on where they should first bring novel interventions attempting to eradicate disparities in health care.

National estimates provided by Haider et al $^{1}$ over the five year period ending in 2010 show no demonstrable improvements in the racial/ethnic disparities in the receipt of analgesics for abdominal pain in the emergency department. Having contemporaneous data is desirable, but not necessary to forge ahead. Relying on the "hope" for spontaneous eradication of disparities left in the Pandora's box is not useful. Where do we go from here? The Institute of Medicine report "Unequal Treatment: Confronting Racial and Ethnic Disparities in Health Care" 10 called for "a comprehensive, multi-level strategy to eliminate health care disparities, addressing health care systems, the legal and regulatory contexts in which they operate, healthcare providers, and their patients". The United States Health and Human Services Disparities Action Plan provides a bold vision towards health equity. ${ }^{11}$ Equipped with "lessons learned" from the first decade of the war on health disparities, we must identify innovative approaches to tackle bias in healthcare delivery and continue to fight for social justice in healthcare.

\section{REFERENCES}

1. Haider, et al. Analgesic access for acute abdominal pain in the emergency department among racial/ ethnic minority patients: a nationwide examination. Medical Care;

2. Office of Disease Prevention and Health Promotion: Access to Health Services. [Accessed October 17, 2015] Healthy People. 2020. http://www.healthypeople.gov/2020/topics-objectives/topic/ Access-to-Health-Services

3. [Accessed October 17, 2015] http://www.huffingtonpost.com/amanda-moore/martin-luther-kinghealth-care_b_2506393.html

4. Todd KH, Samaroo N, Hoffman JR. Ethnicity as a risk factor for inadequate emergency department analgesia. JAMA. 1993; 269(12):1537-9. [PubMed: 8445817]

5. Institute of Medicine (IOM). Relieving Pain in America: A Blueprint for Transforming Prevention, Care, Education, and Research. The National Academies Press; Washington, DC: 2011.

6. Beach, MC.; Cooper, LA.; Robinson, KA.; Price, EG.; Gary, TL.; Jenckes, MW.; Gozu, A.; Smarth, C.; Palacio, A.; Feuerstein, CJ.; Bass, EB.; Powe, NR. Strategies for Improving Minority Healthcare Quality. Agency for Healthcare Research and Quality; Rockville, MD: Jan. 2004 Summary, Evidence Report/Technology Assessment No. 90. (Prepared by the Johns Hopkins University Evidencebased Practice Center, Baltimore, MD.) AHRQ PublicationNo. 04-E008-01

7. Hall WJ, Chapman MV, Lee KM, Merino YM, Thomas TW, Payne BK, Eng E, Day SH, CoyneBeasley T. Implicit Racial/Ethnic Bias Among Health Care Professionals and Its Influence on 
Health Care Outcomes: A Systematic Review. Am J Public Health. 2015:e1-e17. [PubMed: 25602876]

8. United States Department of Health and Human Services. [Accessed October 17, 2015] Hospital Compare. Information for professionals. http://www.hospitalcompare.hhs.gov/

9. Berger ZD, Joy SM, Hutfless S, Bridges JF. Can public reporting impact patient outcomes and disparities? A systematic review. Patient Educ Couns. 2013; 93(3):480-7. [PubMed: 23579038]

10. Institute of Medicine (IOM). Unequal Treatment: Confronting Racial and Ethnic Disparities in Health Care. National Academies Press; Washington, DC: 2003. Available at http:// iom.nationalacademies.org/Reports/2002/Unequal-Treatment-Confronting-Racial-and-EthnicDisparities-in-Health-Care.aspx [Accessed October 17, 2015]

11. U.S. Department of Health and Human Services. HHS Action Plan to Reduce Racial and Ethnic Disparities: A Nation Free of Disparities in Health and Health Care. U.S. Department of Health and Human Services; Washington, D.C.: Apr. 2011 